\title{
ECONOMETRIC ASSESSMENT OF CUSTOMERS' PERSONALITY BIASES AND COMMUNICATION PREFERENCES CORRELATION
}

\author{
Katarina Kostelić, Danijela Križman Pavlović
}

\section{Introduction}

In everyday life, people tend to make various choices, which directly or indirectly bare consequences to a person's economic welfare. One of those choices is the communication preference. Given that the communication is one of the essential pillars of the marketing science, the importance of the analysis of the communication and related topics is imperative. Given the digitalization of the modern world we encounter a situation of data overload while real, "face-to-face", communication diminishes. At this point, it is necessary to gain as much as possible information from the data, especially if the communication is digital. That is one of the reasons for the necessity of quantification of the influencing factors on communication. Therefore, it is relevant to pursue the quantification of the traits and biases which influence people's rationality and consequentially their choices.

Even though the previous research of Roozmand (2011), Nassiri-Mofakham (2008; 2009) and Kostelić (2017) explicitly proved correlation (and/ or causation) of behavioral and psychosocial elements to decision-making in sales process, the link to communication preference prediction is missing. Given that this area has not already been investigated from this approach, it represents a research gap. With this research, we aim to contribute to closing the stated gap.

The data for this research has been gathered online in period of 2013-2015, and previously used for dissertation thesis. For this research, the dependent variable is re-coded, and will be analyzed as a binary variable. That enables the use of prediction models, namely logistic regression with binary dependent variable. Logistic regression with binary dependent variable will be used with both personality traits and personality traits estimators. Although one could assume that models with personality traits as independent variables will offer better predictability, it is not what the analysis shows.

The rest of the article is structured as follows: theoretical overview provides an insight into the topic, methodology section provides details about analysis, results section presents overview of communication preference models, discussion emphasizes implications of the findings and conclusion section provides short summarization with limitations, contributions and possibilities for future research.

\section{Theoretical Overview}

The research regarding people's biases and traits, their influences on rationality and consequentially people's choices is area which covers a part of the marketing science and behavioral economy. Behavioral economists, Camerer (1998) and Rubinstein (1998) have been modelling bounded rationality, while Kahneman (2002) showed groups of possible influences. Njegovanović and Ćosić (2016) emphasize that in our minds, we have a magnificent structure that governs our actions and, in some way, causes awareness of the world around us. Mohlin (2012) provided an overview of development of the thoughts on the theory of the mind. At individual level, boundaries of rationality are characteristics of the individual, heuristics and biases forming a subjective rationality, namely a unique set of boundaries that lead to a specific choice for each individual (Kostelić, 2017). Davis et al. (2007) define the nexus of personality traits and the decision - making. Relevant individual's characteristics for economic decision - making are composed of psychological, sociological and economical elements. Psychosocial elements can be defined by quantification of personality traits, cognitive capacity and value scales. Roozmand et al. (2011) approach to decision- 
making modelling to define the process of the purchase decisions. While designing decisionmaking formal model at interpersonal level, they used the MASQ meta model. NassiriMofakham et al. (2008; 2009) analyzed the bargain process in e-commerce using OCEAN personality type model. Kostelić (2017) and Škare and Kostelić (2016) used quantification of personality traits based on Jung typology and general attitudes to model bounded rationality and consequently decision preferences. In addition, Kostelić (2017) proved OLS and Logit Ordered modelling not to be accurate enough to predict consumers' decisions, while dynamic game theory of asymmetrical information model provided better results. Previous research explicitly proved correlation (and/or causation) of behavioral and psychosocial elements to decision-making.

Pratt (1996) proposed the "electronic personality", a term which denotes that people present themselves differently using computer mediated communications. He found that there is a significant shift in introversion-extraversion and judging - perceiving personality trait in electronic compared to real life personality. Hence, in assessing the population who engage in online activities, whether it is socializing or purchase, their actions will be better assessed using their electronic personality. Villaume and Bodie (2007) examined the relationship between trait-like personality variables, communicator style, and individual listening preferences. They found that people who reported higher levels of psychoticism preferred friendlier and more open communication style, while "more masculine" personality tended to engage in impression leaving arguments. Amiel and Sargent (2004) used the Big Five personality model to assess the motives of internet users. They found that individuals who scored high in neuroticism felt the sense of belonging in the online world, while extraverts reject the community aspect of internet. Ryan and Xenos (2011) examined the link between the personality traits and the use of Facebook. They found that the Facebook users were more extraverted and narcissistic than nonusers, who were more conscientious and lonely. It is interesting to notice that this result collides with Amiel and Sargent's (2004) result, where they found that extraverts reject the community aspect of internet. Johnson and Johnson (2006) examined the relationship of personality traits and internet experience to e-commerce preferences. They found that those who preferred face-to-face communication, were less extroverted, but they found no significant correlation of introversion extraversion personality trait to communication choices. Xiao and Benbasat (2007) examined how recommendation agents (software that gathers information about user, so it could offer recommendations) information and consumer characteristics influence the consumer decision-making process. Horwitz and Pennock (2000) suggest a content recommendation technique based on personality diagnosis using probabilistic determination. Zafari et al. (2017) offer a new solution for a highly accurate hybrid component-based factorized preference model in recommender systems. Their research belongs to the information science field, but they state that they use consumer biases and preferences as model input.

Provided overview shows that personality trait analysis has been investigated from many approaches, in order to explain or predict people's decisions, preferences or behavior. Some of the stated researches investigate the online dimension of people's choices and preferences, up to the level where software gathers information to offer more precise recommendations based on people personality characteristics. Given the overview it can be noticed that there still exists a gap in quantification of the estimators and determination of correlated variables regarding the prediction of communication preferences.

\section{Methodology}

\subsection{Data Collection}

Two of the most commonly used personality tests are Myers-Briggs Type Indication model (MBTI) based on Jung personality typology and the BigFive model (also known as OCEAN) based on Goldberg typology. MBTI model measures four personality traits with the extremes on each pole: extraversion - introversion, sensing - intuitive, thinking - feeling, and judging - perceiving. Four of the Big-Five traits correlate to MBTI traits, and the fifth one is the neuroticism. The BigFive model is primarily used for measurement in psychiatric population due to examination of neuroticism trait. The most commonly used personality measurement for non-psychiatric population is the MBTI test. Murray (1990) pointed out a critique of the MBTI model stating that the test can rather show the preferences 
over real choices (however, he never empirically proved it).

MBTI model, as well as Keirsey's and Bates' (1984) are based on the Jung (1971) personality typology. Those models have been a starting point for the questionnaire composition. The data has been gathered online, from March 2013 until May 2015 in Croatia. During that time, 244 complete questionnaires have been collected. Given that the questionnaire has been distributed online, the conclusions should be made only for the population which uses online services. Respondents' age ranges from 15 to 56 years, with the average age of 28 years. First part of the survey examines the types of personality, while the second part examines communication preferences.

\subsection{Data Analysis}

Personality traits are represented as combined and weighted relative frequencies of the estimators, while choices of consumer preferences act as a binomial variable where a certain choice occurs or doesn't occur.

Binomial dependent variables enable the use of the econometric prediction models, such as logit and probit linear models. Prediction models are stochastic probability models, so they involve a certain amount of inherited randomness which arises from imperfect information. The data analysis has been conducted using both logit and probit prediction modelling with binary dependent variable (Using Gretl GNU software), but logistic analysis provided models with higher percentages of correctly predicted cases and will be presented in this research.

After the analysis of the relative frequencies of the individual traits, the analysis of the answers to specific questions is used to provide an in-depth analysis and to offer practical and direct guideline for approach to customer.

The dependent variable represents choices of communication preferences regarding the communication approach, language use, and information sharing. While answering the question about communication approach preferences respondents ranked: friendly and cordially, professional and cordially, professional and kind, and strictly professional and distanced communication. While choosing the preferred language use, respondents ranked options: simple language with clarifications on examples, simple and common language, expert language with clarifications, and expert language without clarifications. Regarding the information sharing during the interpersonal communication, respondents ranked options: presenting own situation in detail regarding the motives, aims and desires; present the problem, motives and goal in a nutshell; present the problem in short lines, keeping the rest of information; and present the minimum of the necessary information.

For this research, only first-choice preferences are used, and implemented in each choice model as a binomial dependent variable. Dependent variables (communication choice outcomes) are defined as follows:

$O_{i}=\left\{\begin{array}{ll}1 & \text { if the } i-\text { th person made a choice } \\ 0 & \text { otherwise }\end{array}, i=1, \ldots, 12\right.$

The outcome follows Bernoulli distribution, defined with the number of occurrences and the probability of desired outcome.

Hypothesis for each model are set as:

$H_{o} \ldots p_{i}=\hat{p}_{o i}\left(O_{i}=1\right)$

$H_{1} \ldots p_{i} \neq \hat{p}_{o i}\left(O_{i}=0\right)$

Based on a standard probability threshold, the hypothesis interpretation is as follows: if $\hat{p} \geq \tilde{p}$, then $O_{i}=1$, else $O_{i}=0$.

The logistic equation can be stated as:

$o_{i}^{\prime}=\ln \left(\frac{p}{1-p}\right)=\beta_{0}+\beta_{1}(i-e)+\beta_{2}(n-s)+\beta_{3}(t-f)+\beta_{4}(j-p)$ or, in terms of probability, it is:

$\hat{p}=\frac{e^{\beta_{0}+\beta_{1}(i-e)+\beta_{2}(n-s)+\beta_{3}(t-f)+\beta_{4}(j-p)}}{e^{\beta_{0}+\beta_{1}(i-e)+\beta_{2}(n-s)+\beta_{3}(t-f)+\beta_{4}(j-p)}+1}=\frac{e^{o_{i}^{\prime}}}{e^{o_{i+1}^{\prime}}}$

To test hypothesis, commonly used tests will be conducted: log likelihood test and Wald test statistics. In addition, confusion matrix will be discussed.

To test hypothesis, likelihood ratio test is used. It is statistic test which provides ratio of the likelihood for the hypothesized parameter values to the likelihood of the data at maximum likelihood estimate, where degrees of freedom are equal to the number of observations for big data sets. The test values are approximately equal to $\chi_{i}^{2}$.

Wald test statistics is a function which measures ratio of squared difference of the maximum likelihood estimate and hypothesised value and estimate of the standard deviation of maximum likelihood estimate. The result provides the z-score for the observed variable, namely the deviation from the mean expressed in standard deviation. 
McFadden $\mathrm{R}$ squared $\left(R_{\text {McFadden }}^{2}\right)$ is not going to be used as the criteria for the model rejection. $R_{\text {McFadden }}^{2}$ is based on log-likelihood and while a certain variable can have reasonable effect on the outcome, that diminishes when applying logarithm. That is one of the reason why $R_{\text {McFadden }}^{2}$ takes rather small values for fitted logistic models. To increase $R_{\text {McFadden }}^{2}$ value, it is necessary to increase the difference in probability of certain event occurrence, hence influence data - which would rather be avoided in this research.

Model prediction will be discussed using results of confusion matrix.

As a hypothesis rejection criterion, $p$-value is going to be discussed at $95 \%$ confidence level, respectively 0.05 significance level.

\section{Results}

\subsection{Independent Variables: Personality Traits}

Tab. 1 contains an overview of the analysis of personality traits and the first-choice communication preferences modelling using binomial logistic regression. There are twelve models, divided into three sets of four models, regarding the dependent variables: communication approach/style, language use, and information sharing preferences.

The first set of four models (M1-M4) relate to question of communication approach preferences. First model describes "friendly and cordially" first-choice communication preference.

According to the calculation, first model (M1, first column) is derived as follows (Eq. 1):

$$
\hat{p}_{1}=\frac{e^{-1.70323+1.24374(i-e)+0.963116(n-s)-1.70946(f-t)+0.106833(p-j)}}{e^{-1.70323+1.24374(i-e)+0.963116(n-s)-1.70946(f-t)+0.106833(p-j)}+1}=\frac{e^{O_{1}^{\prime}}}{e^{O_{1}^{\prime}}+1}
$$

\section{Tab. 1: Models of first-choice communication preferences based on personality traits}

\begin{tabular}{|c|c|c|c|c|c|c|c|c|c|c|c|c|}
\hline $\begin{array}{l}\text { Independent } \\
\text { variables (perso- } \\
\text { nality traits } \\
\text { estimators) }\end{array}$ & M1 & M2 & M3 & M4 & M5 & M6 & M7 & M8 & M9 & M10 & M11 & M12 \\
\hline Const & $-1.703^{*}$ & -0.774 & 0.119 & -4.499 & 0.31 & -1.124 & $-2.0749^{\star}$ & -2.237 & $-\underset{\star \star \star}{-2.825}$ & 0.782 & -1.428 & -1.744 \\
\hline i-e & $1.244^{*}$ & -0.186 & -0.583 & -3.738 & -0.087 & -0.236 & 0.623 & -0.572 & $1.775^{* *}$ & 0.0368 & -1.102 & -2.651 * \\
\hline$n-s$ & 0.963 & 0.292 & -1.28 & $6.441 *$ & -0.332 & $2.431^{* *}$ & $-\underset{* \star \star}{-4.393}$ & 2.891 & $2.672^{* *}$ & -0.144 & $-2.406^{*}$ & -2.32 \\
\hline$f-t$ & $-1.709^{*}$ & -1.211 & $1.933^{* *}$ & -0.066 & -0.371 & -0.507 & 1.626 & -1.497 & -0.817 & -0.085 & 0.385 & 1.572 \\
\hline$p-j$ & 0.107 & -0.332 & 0.378 & -2.447 & 0.149 & -0.673 & 1.951 & -4.53 & -0.313 & -1.149 & $2.485^{* *}$ & 0.297 \\
\hline $\begin{array}{l}\text { Number of } \\
\text { cases 'correctly } \\
\text { predicted' }\end{array}$ & $\begin{array}{c}189 \\
(77.5 \%)\end{array}$ & $\begin{array}{c}199 \\
(81.6 \%)\end{array}$ & $\begin{array}{c}148 \\
(60.7 \%)\end{array}$ & $\begin{array}{c}241 \\
(98.8 \%)\end{array}$ & $\begin{array}{c}126 \\
(51.6 \%)\end{array}$ & $\begin{array}{c}161 \\
(66.0 \%)\end{array}$ & $\begin{array}{c}207 \\
(84.8 \%)\end{array}$ & $\begin{array}{c}241 \\
(98.8 \%)\end{array}$ & $\begin{array}{c}183 \\
(75.3 \%)\end{array}$ & $\begin{array}{c}124 \\
(51.0 \%)\end{array}$ & $\begin{array}{c}193 \\
(79.4 \%)\end{array}$ & $\begin{array}{c}232 \\
(95.5 \%)\end{array}$ \\
\hline $\begin{array}{l}f(\text { beta } x) \text { at mean } \\
\text { of independent } \\
\text { vars }\end{array}$ & 0.169 & 0.149 & 0.243 & 0.006 & 0.25 & 0.216 & 0.121 & 0.009 & 0.179 & 0.25 & 0.158 & 0.032 \\
\hline $\begin{array}{l}\text { Likelihood ratio } \\
\text { test: } \\
\text { Chi-square }\end{array}$ & $\begin{array}{l}8.57322 \\
{[0.0727]}\end{array}$ & $\begin{array}{l}1.71255 \\
{[0.7884]}\end{array}$ & $\begin{array}{l}10.3718 \\
{[0.0346]}\end{array}$ & $\begin{array}{l}4.61145 \\
{[0.3295]}\end{array}$ & $\begin{array}{c}0.394559 \\
{[0.9829]}\end{array}$ & $\begin{array}{l}6.67677 \\
{[0.1540]}\end{array}$ & $\begin{array}{l}12.9734 \\
{[0.0114]}\end{array}$ & $\begin{array}{l}2.72622 \\
{[0.6046]}\end{array}$ & $\begin{array}{l}15.6127 \\
{[0.0036]}\end{array}$ & $\begin{array}{l}1.88027 \\
{[0.7578]}\end{array}$ & $\begin{array}{l}10.9361 \\
{[0.0273]}\end{array}$ & $\begin{array}{l}7.21233 \\
{[0.1251]}\end{array}$ \\
\hline $\begin{array}{l}\text { McFadden } \\
\text { R-squared }\end{array}$ & 0.032919 & 0.007341 & 0.031211 & 0.14253 & 0.001167 & 0.021834 & 0.060503 & 0.084261 & 0.057013 & 0.005582 & 0.043796 & 0.080506 \\
\hline $\begin{array}{l}\text { Correctly } \\
\text { predicted } 1\end{array}$ & 0 & 0 & 117 & 0 & 85 & 0 & 2 & 0 & 2 & 54 & 1 & 0 \\
\hline $\begin{array}{l}\text { Correctly } \\
\text { predicted } 0\end{array}$ & 189 & 100 & 31 & 241 & 41 & 161 & 205 & 241 & 181 & 70 & 192 & 232 \\
\hline $\begin{array}{l}\text { Predicted } 1 \\
\text { Actual } 0\end{array}$ & 0 & 0 & 72 & 0 & 79 & 5 & 0 & 0 & 1 & 53 & 0 & 0 \\
\hline $\begin{array}{l}\text { Predicted } 0 \\
\text { Actual } 1\end{array}$ & 55 & 45 & 24 & 3 & 39 & 78 & 37 & 3 & 59 & 66 & 50 & 11 \\
\hline
\end{tabular}


Statistically significant variables at 0.1 significance level are the constant, and personality traits: intuitive - sensing and feeling - thinking. The exact marginal effect to the dependent variable can be read out from the slopes at the mean. However, coefficients point out the same direction of the influence of the statistically significant variables. The coefficients suggest that the more intuitive (or less sensing) and more feeling (or less thinking) traits expressed, the outcome converges to occurrence of the first-choice of the friendly and cordially communication preference. Simulation shows that 189 or $77.5 \%$ of the outcomes are correctly predicted. $R_{\text {McFadden }}^{2}$ points out to a very small prediction level. The confusion matrix shows that the model has failed to predict 55 choices of this communication preference which denotes the type II error. The hypothesis should be rejected at 0.05 significance level.

Simulation of the "professional and cordially" communication preference (M2) shows that 199 or $81.6 \%$ of the outcomes are correctly predicted. However, there are no significant variables. Confusion matrix shows that there are 45 outcomes predicted as 0 , but actual value is 1 which points out to a type II error. Given the likelihood ratio test, the probability that the $\chi^{2}$ data value exceeds the $\chi^{2}$ is 0.7884 , and the null-hypothesis should be rejected at 0.05 significance level.

The analysis of the "professional and kind" communication preference (M3) shows that statistically significant variable at 0.05 significance level is personality trait thinking - feeling. Confusion matrix points out that 72 outcomes are predicted as value 1 while their actual value is 0 , which points out to type I error. The other 24 miss-predicted outcomes represent the type II error of this model. There are only 148 correctly predicted outcomes, but likelihood ratio test leads to conclusion that the null hypothesis should not be rejected at the 0.05 significance level.

The analysis of the "strictly professional and distanced" communication preference (M4) points out to the personality trait intuitive sensing as a statistically significant variable. The number of correctly predicted cases is $98.8 \%$, with only 3 miss-predicted cases. However, the likelihood ratio test leads us to conclusion that the hypothesis should be rejected.

The next set of four models (M5-M8), regards to the preferred language use.
The analysis of the "simple language with clarifications on examples" (M5) points out that there are no statistically significant independent variables and there is barely over half of the cases correctly predicted. Likelihood ratio test points out that the null-hypothesis should be rejected at the 0.05 significance.

The M6 column provides an analysis for the communication preference of the "simple, common language". The personality trait intuition - sensing is a statistically significant variable at 0.95 confidence level. Simulation shows that there are $66 \%$ of the correctly predicted cases by the model. Both type I error (78 cases) and type II error (5 cases) are present in this model. In addition, likelihood ratio test suggests that the null - hypothesis should be rejected at 0.05 significance level.

The M7 column contains the analysis of the "expert language with clarifications" communication first-choice. Statistically significant variables are the constant and intuitive - sensing personality trait. There are $84.8 \%$ correctly predicted outcomes. Type II error is present in the model. LRT suggests that the null-hypothesis should not be rejected at the 0.05 significance level.

Even though there are no statistically significant variables, the model of "expert language use without clarifications" simulation (M8) predicted $98.8 \%$ outcomes correctly, with only 3 miss-predicted outcomes. However, LRT leads to conclusion that the null-hypothesis should be rejected at the 0.05 significance level.

Following set of four models (M9-M12) regards to information sharing.

The analysis of the "presenting own situation in detail regarding the motives, aims and desires" (M9) points out that the constant, as well as personality traits introversion - extraversion and feeling - thinking are statistically significant variables. The simulation provides information that the model correctly predicted $75.3 \%$ outcomes. LRT points out that the null - hypothesis should not be rejected at the 0.05 significance level.

The analysis presented in M10, does not point out any significant variable. Both type I and type II errors are large in this model. LRT shows that the null-hypothesis should be rejected.

Statistically significant variables for model presented in M11, are the intuition - sensing and perceiving - judging personality traits. The 
simulation shows that $79.4 \%$ of the cases are correctly predicted. Miss - predicted cases represent the error type II in this model. LRT shows that the null - hypothesis should not be rejected at 0.05 significance level.

The analysis of the first-choice of "minimum of information exposure" preference (M12) points out that introversion - extraversion personality trait is a statistically significant variable with negative coefficient. That means that if extraversion is more expressed it will lead to smaller value of the dependent value, that is, to zero as the choice of this communication preference. The simulation shows that $95.5 \%$ cases are correctly predicted by this model, but the LRT shows that the null - hypothesis should be rejected at $5 \%$ significance.

\subsection{Independent Variable: Personality Estimators}

To provide a more thorough analysis of the biases which influence communication preferences, personality estimators are used as independent variables, while the dependent variables stay the same. The results are summarized in Tab. 2 . The table contains a list of the personality traits estimators, precisely, a set of claims with Yes/ No responses (for this analysis, "Yes" is coded as 1 , and "No" as 0 ). Models are stated in the columns, with statistically significant variables emphasised with significance level.

All the twelve models presented in the Tab. 2 show significantly low LRT p-values, which leads to conclusion that the null-hypothesis should not be rejected. The correctly predicted

\begin{tabular}{|c|c|c|c|c|c|c|c|c|c|c|c|c|}
\hline Tab. 2: & $\begin{array}{l}\text { Mo } \\
\text { esti }\end{array}$ & $\begin{array}{l}5 \text { of } \\
\text { tor }\end{array}$ & $\begin{array}{l}\text { st-ch } \\
\text { Part 1) }\end{array}$ & & mu & tic & refe & & sed & pe & ality & \\
\hline $\begin{array}{l}\text { Independent } \\
\text { variables }\end{array}$ & M1 & M2 & M3 & M4 & M5 & M6 & M7 & M8 & M9 & M10 & M11 & M12 \\
\hline Q1 & $2.85^{* *}$ & 2.28 & $-2.56^{\star \star}$ & & 0.42 & -1.25 & 2.13 & & 2.64 & $-1.87^{\star}$ & -1.07 & \\
\hline Q2 & -0.45 & 2.05 & 0.102 & & 0.393 & 0.008 & -0.82 & & 0.67 & 0.21 & $-1.96^{*}$ & \\
\hline Q3 & -0.32 & 0.92 & 0.198 & & 0.293 & 0.903 & $-5.91^{\star \star \star}$ & & $-1.69^{*}$ & $1.828^{\star *}$ & -1.26 & \\
\hline Q4 & $2.207^{\star \star \star}$ & 1.513 & $-2.10^{\star \star \star}$ & & 0.544 & -0.12 & $-1.96^{*}$ & & 1.008 & -0.17 & -0.33 & \\
\hline Q5 & 0.822 & 4.013 & $-1.299^{* \star \star}$ & & 0.084 & -0.58 & 0.734 & & $1.506^{\star \star}$ & -0.17 & $-2.41^{* *}$ & \\
\hline Q6 & 0.074 & 0.082 & -0.04 & & 0.471 & $-1.02^{* \star}$ & 0.291 & & 0.547 & 0.281 & -1.39 & \\
\hline Q7 & $1.258^{* \star}$ & 3.870 & $-1.80^{* \star \star}$ & & 0.332 & -0.53 & -0.295 & & -0.999 & -0.03 & $2.206^{\star \star}$ & \\
\hline Q8 & 0.135 & -2.37 & $1.088^{\star \star}$ & & 0.653 & -0.59 & -0.91 & & $1.26^{*}$ & -0.49 & -0.56 & \\
\hline Q9 & $-1.39^{* \star}$ & -2.58 & $1.43^{\star \star \star}$ & & $0.749^{*}$ & $-0.93^{\star}$ & 1.64 * & & $1.344^{\star *}$ & -0.68 & 0.420 & \\
\hline Q10 & -0.29 & -0.8 & 0.34 & & -0.3 & 0.158 & -0.49 & & -0.88 & -0.18 & 1.504 & \\
\hline Q11 & $1.165^{\star}$ & -1.1 & -0.23 & & -0.13 & -0.07 & -0.31 & & 0.022 & 0.502 & -1.09 & \\
\hline Q12 & $-1.55^{\star \star}$ & 3.193 & 0.011 & & -0.46 & 0.252 & 0.385 & & 0.388 & -0.08 & -1.29 & \\
\hline Q13 & -0.46 & -1.08 & 0.52 & & 1.22 ** & $-2.03^{\star \star \star}$ & 1.506 & & $2.462^{\star \star \star}$ & $-1.23^{\star \star}$ & $-3.56^{\star \star}$ & \\
\hline Q14 & -0.17 & -1.59 & 0.287 & & -0.46 & 0.404 & 0.089 & & $1.269^{* \star}$ & -0.4 & -0.26 & \\
\hline Q15 & -0.94 & 1.84 & -0.27 & & -0.53 & 0.793 & 0.323 & & $-2.39^{\star \star \star}$ & $1.53^{* \star *}$ & -0.88 & \\
\hline Q16 & 0.887 & -1.36 & -0.56 & & 0.001 & -0.07 & 0.138 & & -0.26 & 0.326 & -1.59 & \\
\hline Q17 & $1.763^{\star \star *}$ & -1.11 & -0.5 & & -0.58 & $1.096^{\star \star}$ & -0.04 & & -0.79 & $1.48^{* * *}$ & $-2.41^{* \star}$ & \\
\hline Q18 & 0.811 & 2.42 & $-0.99 *$ & & -0.35 & 0.267 & $-2.39^{\star \star}$ & & 0.453 & 0.66 & $-4.13^{* * *}$ & \\
\hline Q19 & -1.19 & 0.293 & 0.281 & & 0.084 & 0.629 & -1.32 & & -0.67 & 0.197 & 0.917 & \\
\hline Q20 & 0.61 & -3.52 & -0.30 & & -0.12 & 0.667 & -0.69 & & -0.91 & -0.42 & $2.276^{* \star}$ & \\
\hline Q21 & $-0.96^{*}$ & 1.193 & 0.156 & & $-0.76^{*}$ & $0.970^{*}$ & $1.902^{*}$ & & -0.41 & 0.617 & -1.06 & \\
\hline Q22 & 1.732 & 2.464 & $-1.61^{* *}$ & & -0.33 & -0.68 & -0.19 & & 1.584 & -0.62 & -1.83 & \\
\hline Q23 & $-2.21^{\star \star *}$ & 0.617 & $0.981^{*}$ & & -0.80 & 0.662 & $2.187^{\star \star}$ & & 0.729 & 0.537 & -0.51 & \\
\hline Q24 & -0.47 & -1.07 & 0.468 & & 0.644 & 0.032 & $-1.88^{\star}$ & & -0.14 & -0.12 & -0.06 & \\
\hline Q25 & 0.567 & -1.04 & -0.02 & & 0.403 & -0.19 & -0.61 & & $-1.51^{\star \star}$ & 0.784 & 0.114 & \\
\hline Q26 & $1.967^{\star \star}$ & -1.36 & $-1.15^{*}$ & & 0.375 & -0.33 & -1.34 & & 1.267 & -0.28 & 1.041 & \\
\hline Q27 & 0.278 & 0.923 & -0.1 & & -0.43 & 0.346 & 0.205 & & -0.28 & -0.21 & 0.887 & \\
\hline
\end{tabular}




\begin{tabular}{|c|c|c|c|c|c|c|c|c|c|c|c|c|}
\hline Tab. 2: & $\begin{array}{l}\text { Mod } \\
\text { estir }\end{array}$ & of & $\begin{array}{l}\text { st-cl } \\
\text { Part } 2\end{array}$ & & nur & ation & efe & & sed & pe & rality & \\
\hline $\begin{array}{l}\text { Independent } \\
\text { variables }\end{array}$ & M1 & M2 & M3 & M4 & M5 & M6 & M7 & M8 & M9 & M10 & M11 & M12 \\
\hline Q28 & -0.64 & -0.59 & 0.613 & & -0.50 & 0.011 & $2.414^{\star \star}$ & & 1.021 & -0.46 & -0.05 & \\
\hline Q29 & 0.499 & -0.44 & -0.17 & & $1.033^{\star \star}$ & -0.52 & $-1.96^{* \star}$ & & -0.31 & 0.473 & $-1.54^{*}$ & \\
\hline Q30 & 0.787 & -2.10 & 0.06 & & $3.401^{\star \star}$ & 0.199 & -2.84 & & 1.677 & -1.27 & -11.6 & \\
\hline Q31 & $-1.75^{* \star *}$ & -0.01 & $1.122^{\star *}$ & & $-1.48^{\star \star \star}$ & $1.502^{\star \star \star}$ & 0.777 & & -1.01 & 0.101 & $2.178^{\star}$ & \\
\hline Q32 & $-1.91^{*}$ & 5.084 & -0.81 & & 0.304 & -0.23 & 0.955 & & 0.486 & 0.198 & 2.16 & \\
\hline Q33 & 0.174 & -2.19 & 0.656 & & 0.237 & -0.43 & 0.903 & & -0.15 & 0.406 & -1.37 & \\
\hline Q34 & 0.177 & -0.97 & -0.27 & & -0.28 & 0.631 & -1.18 & & -0.27 & $1.11^{*}$ & $-2.06^{\star}$ & \\
\hline Q35 & 1.111 & -5.99 & 0.966 & & -0.15 & 1.452 & -1.81 & & $-8.96^{* * *}$ & $2.473^{*}$ & 3.948 & \\
\hline Q36 & -1.24 & 2.136 & 0.2 & & $-2.41^{\star}$ & -1.59 & $4.603^{*}$ & & -0.61 & 0.127 & 15.22 & \\
\hline Q37 & $-1.48^{* *}$ & -3.15 & $2.369^{* \star *}$ & & 0.423 & -0.53 & 1.228 & & $-1.84^{* *}$ & $0.87^{*}$ & $2.879^{* *}$ & \\
\hline Q38 & -0.25 & -1.56 & 0.625 & & 0.412 & -0.52 & 1.015 & & 0.398 & $-0.95^{\star *}$ & $2.287^{\star *}$ & \\
\hline Q39 & -0.15 & 4.225 & $-1.04^{*}$ & & 0.585 & $-1.32^{\star \star}$ & $1.887^{*}$ & & -0.66 & 0.18 & 1.158 & \\
\hline Q40 & -0.61 & 1.794 & 0.04 & & -0.63 & -0.6 & $3.02^{* \star \star}$ & & $1.389^{* *}$ & -0.37 & $-2.61^{\star \star}$ & \\
\hline Q41 & 0.121 & 1.776 & -0.47 & & 0.54 & 0.148 & 1.13 & & -0.03 & -0.08 & 1.214 & \\
\hline Q42 & -0.22 & 4.59 & $-1.29^{\star \star \star}$ & & 0.595 & -0.44 & $-1.99^{* \star}$ & & -0.14 & -0.17 & -0.29 & \\
\hline Q43 & 0.198 & 3.503 & $-0.96^{\star \star}$ & & $0.745^{\star}$ & -0.37 & -0.14 & & 0.378 & -0.2 & 1.387 & \\
\hline Q44 & $2.679^{\star \star *}$ & 0.086 & $-1.43^{\star *}$ & & -0.004 & $1.687^{\star *}$ & $-3.86^{\star * \star}$ & & 0.218 & -0.09 & 0.12 & \\
\hline Q45 & $-1.17^{\star}$ & -0.8 & 0.764 & & 0.055 & 0.449 & 0.644 & & 0.44 & $-1.46^{\star \star \star}$ & $2.207^{\star *}$ & \\
\hline Q46 & 1.38 & 8.025 & -0.98 & & 0.798 & -0.25 & $-3.33^{* *}$ & & -1.13 & 0.463 & -0.25 & \\
\hline Q47 & -0.52 & -4.33 & $1.63^{* * *}$ & & 0.528 & $-1.36^{\star \star}$ & $1.605^{*}$ & & 0.048 & -0.35 & 0.8 & \\
\hline Q48 & -0.53 & -0.61 & 0.643 & & -0.04 & -0.57 & 0.367 & & $1.696^{\star \star}$ & -0.59 & -1.22 & \\
\hline Q49 & 0.097 & -3.28 & 0.651 & & 0.269 & -0.29 & 0.725 & & -0.08 & -0.40 & $1.706^{\star}$ & \\
\hline Q50 & 0.583 & -2.65 & 0.341 & & -0.26 & 0.458 & -0.47 & & -0.43 & 0.079 & 0.65 & \\
\hline Q51 & -0.44 & -1.03 & $0.797^{\star}$ & & -0.36 & $1.185^{\star \star}$ & -0.14 & & $-1.28^{* \star}$ & 0.268 & 0.879 & \\
\hline Q52 & -0.16 & -0.96 & -0.08 & & 0.383 & $-1.69^{\star \star *}$ & $2.716^{\star \star \star}$ & & 0.42 & -0.51 & -0.39 & \\
\hline Q53 & $1.436^{* \star}$ & -0.32 & -0.87 & & -0.77 & $1.606^{\star \star *}$ & -0.99 & & 0.864 & -0.19 & -0.97 & \\
\hline Q54 & $-2.54^{\star \star \star}$ & 2.338 & 0.616 & & 0.36 & -0.84 & 1.416 & & 0.923 & $-0.96^{*}$ & $2.522^{*}$ & \\
\hline Q55 & 0.175 & -1.32 & -0.64 & & -0.55 & -0.46 & $2.983^{\star \star}$ & & 0.627 & -0.6 & 1.85 & \\
\hline Q56 & -0.49 & 2.06 & -0.24 & & -0.54 & 1.087 & -0.95 & & 0.005 & -0.31 & 1.016 & \\
\hline Q57 & 0.396 & -1.95 & 0.815 & & -0.07 & -0.23 & 0.195 & & -0.28 & 0.452 & -0.64 & \\
\hline Q58 & 0.446 & -1.59 & 0.138 & & -0.37 & 0.164 & 0.285 & & -0.34 & -0.28 & 1.153 & \\
\hline Q59 & $-1.11^{*}$ & -0.6 & $0.893^{*}$ & & $-0.9^{* *}$ & $0.996^{*}$ & -0.45 & & -0.2 & -0.16 & $2.017^{\star *}$ & \\
\hline Q60 & 1.063 & 0.861 & -0.55 & & 0.224 & $-1.2^{*}$ & 1.541 & & -0.48 & 0.112 & -0.18 & \\
\hline Q61 & $1.437^{* *}$ & -0.01 & -0.74 & & -0.59 & $1.719^{\star \star \star}$ & $-2.82^{\star * \star}$ & & $-1.15^{*}$ & 0.81 & 0.736 & \\
\hline Q62 & -0.51 & 1.005 & 0.156 & & -0.44 & -0.06 & -0.24 & & -1.03 & $1.169^{* \star}$ & $-3.47^{\star \star}$ & \\
\hline Q63 & -0.72 & -0.61 & 0.41 & & -0.07 & 0.134 & 0.065 & & $1.223^{* \star}$ & -0.7 & -0.16 & \\
\hline Q64 & -0.04 & -2.37 & 0.569 & & -0.39 & -0.08 & 0.968 & & -0.89 & -0.38 & $2.243^{\star *}$ & \\
\hline Q65 & -0.46 & -0.62 & 0.243 & & $-1.66^{* \star *}$ & $2.038^{* * *}$ & -0.5 & & -0.33 & 0.333 & $-3.58^{\star \star \star}$ & \\
\hline Q66 & -0.33 & 1.006 & -0.01 & & -0.19 & 0.453 & -0.53 & & $-1.23^{* \star}$ & $-0.76^{\star}$ & $4.564^{\star \star \star}$ & \\
\hline Q67 & 0.628 & -0.69 & -0.19 & & 0.006 & -0.19 & 1.304 & & $1.03^{*}$ & -0.15 & -1.2 & \\
\hline Q68 & -0.53 & 1.524 & -0.3 & & $0.785^{*}$ & 0.339 & $-3.96^{* \star *}$ & & -0.05 & -0.49 & -0.4 & \\
\hline Q69 & 1.321 & -1.43 & 0.413 & & -0.05 & -0.35 & 1.172 & & -1.12 & 0.205 & 0.110 & \\
\hline Q70 & 1.006 & 1.957 & -0.7 & & 0.176 & -0.25 & -0.17 & & 0.044 & 0.502 & -1.88 & \\
\hline
\end{tabular}




\begin{tabular}{|c|c|c|c|c|c|c|c|c|c|c|c|c|}
\hline \multirow{2}{*}{$\begin{array}{c}\text { Tab. 2: } \\
\text { Independent } \\
\text { variables }\end{array}$} & \multicolumn{12}{|c|}{$\begin{array}{l}\text { Models of first-choice communication preferences based on personality } \\
\text { estimators (Part 3) }\end{array}$} \\
\hline & M1 & M2 & M3 & M4 & M5 & M6 & M7 & M8 & M9 & M10 & M11 & M12 \\
\hline Q71 & -0.13 & -3.07 & $1.208^{*}$ & & 0.408 & -0.16 & -1.13 & & 0.514 & -0.02 & 0.409 & \\
\hline Q72 & -0.84 & -2.53 & $1.432^{*}$ & & -0.66 & 0.823 & 0.580 & & -1.37 & 1.026 & -0.21 & \\
\hline Constant & $-6.58^{* *}$ & $-7.14^{\star *}$ & 1.583 & & -0.43 & -2.12 & -1.97 & & 3.712 & -1.43 & $-6.91^{* *}$ & \\
\hline $\begin{array}{l}\text { Number } \\
\text { of cases } \\
\text { 'correctly } \\
\text { predicted' }\end{array}$ & $\begin{array}{c}202 \\
(87.8 \%)\end{array}$ & $\begin{array}{c}204 \\
(88.7 \%)\end{array}$ & $\begin{array}{c}183 \\
(79.6 \%)\end{array}$ & $\begin{array}{c}\text { Perfect } \\
\text { prediction } \\
\text { obtained: } \\
\text { No MLE } \\
\text { exists }\end{array}$ & $\begin{array}{c}170 \\
(73.9 \%)\end{array}$ & $\begin{array}{c}191 \\
(83.0 \%)\end{array}$ & $\begin{array}{c}205 \\
(89.1 \%)\end{array}$ & $\begin{array}{c}\text { Perfect } \\
\text { prediction } \\
\text { obtained: } \\
\begin{array}{c}\text { No MLE } \\
\text { exists }\end{array} \\
\end{array}$ & $\begin{array}{c}197 \\
(86.0 \%)\end{array}$ & $\begin{array}{c}179 \\
(78.2 \%)\end{array}$ & $\begin{array}{c}210 \\
(91.7 \%)\end{array}$ & $\begin{array}{c}\text { Perfect } \\
\text { prediction } \\
\text { obtained: } \\
\text { No MLE } \\
\text { exists }\end{array}$ \\
\hline $\begin{array}{c}f(\text { beta' } x) \text { at } \\
\text { mean of } \\
\text { independent } \\
\text { vars }\end{array}$ & 0.419 & 0.384 & 0.494 & & 0.501 & 0.466 & 0.372 & & 0.438 & 0.501 & 0.414 & \\
\hline $\begin{array}{l}\text { Likelihood } \\
\text { ratio test: } \\
\text { Chi-square }\end{array}$ & $\begin{array}{l}94.2336 \\
{[0.0405]}\end{array}$ & $\begin{array}{l}107.914 \\
{[0.0039]}\end{array}$ & $\begin{array}{l}108.265 \\
{[0.0037]}\end{array}$ & & $\begin{array}{l}86.1317 \\
{[0.1224]}\end{array}$ & $\begin{array}{l}93.5176 \\
{[0.0451]}\end{array}$ & $\begin{array}{l}92.1817 \\
{[0.0547]}\end{array}$ & & $\begin{array}{l}106.398 \\
{[0.0052]}\end{array}$ & $\begin{array}{l}100.904 \\
{[0.0139]}\end{array}$ & $\begin{array}{l}136.144 \\
{[0.0000]}\end{array}$ & \\
\hline $\begin{array}{l}\text { McFadden } \\
\text { R-squared }\end{array}$ & 0.383 & 0.5 & 0.346 & & 0.27 & 0.325 & 0.447 & & 0.407 & 0.318 & 0.566 & \\
\hline $\begin{array}{l}\text { Correctly } \\
\text { predicted } 1\end{array}$ & 30 & 22 & 113 & & 86 & 47 & 19 & & 38 & 82 & 38 & \\
\hline $\begin{array}{l}\text { Correctly } \\
\text { predicted } 0\end{array}$ & 172 & 182 & 70 & & 84 & 144 & 186 & & 159 & 97 & 172 & \\
\hline \begin{tabular}{c|} 
Predicted 1 \\
Actual 0
\end{tabular} & 6 & 7 & 26 & & 30 & 13 & 6 & & 11 & 22 & 7 & \\
\hline $\begin{array}{c}\text { Predicted } 0 \\
\text { Actual } 1\end{array}$ & 22 & 19 & 21 & & 30 & 26 & 19 & & 21 & 28 & 12 & \\
\hline$H_{0}$ & $\begin{array}{l}\text { Prob (Friendly } \\
\text { Cordially }=0 \mid \\
Q 35=0)=1\end{array}$ & $\begin{array}{c}\text { Prob } \\
\text { (Professionally } \\
\text { Cordially }= \\
1)=1 \\
\end{array}$ & $\begin{array}{c}\text { Prob } \\
\text { (Professionally } \\
\text { Kind }=1)=1\end{array}$ & $\begin{array}{l}\text { Prob (Strictly } \\
\text { Professionally } \\
=0)=1\end{array}$ & $\begin{array}{c}\text { Prob }(\text { Simple } \\
\text { Clarific }= \\
1)=1\end{array}$ & $\begin{array}{c}\text { Prob (Simple } \\
\text { Common }= \\
1)=1\end{array}$ & $\begin{array}{c}\text { Prob } \\
\text { (Expert with } \\
\text { Clarification }= \\
1)=1\end{array}$ & $\begin{array}{c}\text { Prob } \\
\text { (Expert No } \\
\text { Clarification }= \\
0)=1\end{array}$ & $\left\{\begin{array}{c}\text { Prob (Detail }= \\
\text { 1) }=1\end{array}\right.$ & $=\begin{array}{c}\text { Prob (Problem } \\
\text { Motives Goal } \\
=1)=1\end{array}$ & $\begin{array}{c}\text { Prob (Problem } \\
\text { strict lines }= \\
1)=1\end{array}$ & $\begin{array}{c}\text { Prob (Minimum } \\
\text { Information = } \\
0)=1\end{array}$ \\
\hline Notes & Dropping Q35 & \begin{tabular}{|c|} 
Incomplete \\
obs. dropped: \\
13
\end{tabular} & \begin{tabular}{|c|} 
Incomplete \\
obs. dropped: \\
13
\end{tabular} & & \begin{tabular}{|c|} 
Incomplete \\
obs. dropped: \\
13
\end{tabular} & $\begin{array}{c}\text { Incomplete } \\
\text { obs. dropped: } \\
13\end{array}$ & \begin{tabular}{|c|} 
Incomplete \\
obs. dropped: \\
13
\end{tabular} & & \begin{tabular}{|c|} 
Incomplete \\
obs. dropped: \\
14
\end{tabular} & $\begin{array}{c}\text { Incomplete } \\
\text { obs. dropped: } \\
14\end{array}$ & \begin{tabular}{|c|} 
Incomplete \\
obs. dropped: \\
14
\end{tabular} & \\
\hline
\end{tabular}

Source: own calculation

cases vary from $73.9 \%$ to $91.79 \%$. If we observe the models within each set as complementary, it ostensibly increases the overall predictivity. $R_{\text {McFadden }}^{2}$ shows significantly higher values and points out that in this set of models, variations of independent variables explain from $27.015 \%$ to $56.642 \%$ of variations of dependent variables, while the rest remains unexplained (model error, inherited randomness or circumstantial influences). Models could not be derived for three dependent variables, given that maximum likelihood estimators could not be calculated due to perfect prediction obtained.

The model of the "friendly and cordially" communication preferences correctly predicted $87.8 \%$ of the outcomes. Statistically significant variables with positive coefficients (respectively, slopes at the mean) are: Q1, Q4, Q7, Q11, Q17, Q26, Q44, Q53, Q61; while significant variables with negative coefficients are: the constant,
Q9, Q12, Q21, Q23, Q31, Q32, Q37, Q45, Q54, Q59. For example, that means that the person who stated that the claim Q1 "You like to be involved in active and dynamic activities and jobs" (and/ or other significant variables with positive coefficients) refers to her/ himself, will also be more likely to choose this communication preference. As opposed to first situation, the person who stated that the claim Q12 "You believe that the best decisions are those which are easy to change" (and/ or other significant variables with negative coefficients) refers to her/ him-self, will be more likely not to choose friendly and cordially communication preference (statements for each independent variable can be found in the Tab. 2 and Appendix and interpreted in a similar manner).

The model of the "professional and cordial" first-choice communication preference correctly predicted $88.7 \%$ of cases. Statistically 
significant variables with positive coefficients are: Q2, Q5, Q7, Q12, Q15, Q18, Q32, Q39, Q42, Q43, Q46, Q70; and statistically significant variables with negative coefficients are: the constant, Q8, Q9, Q20, Q33, Q35, Q37, Q47, Q49, Q50, Q64, Q71.

The model of the "professional and kind" first-choice communication preference correctly predicted $79.6 \%$ of cases. Statistically significant variables with positive coefficients are: Q8, Q9, Q23, Q31, Q37, Q47, Q51Q59, Q71, Q72; and statistically significant variables with negative coefficients are: Q1, Q4, Q5, Q7, Q16, Q22, Q26, Q39, Q42, Q43, Q44.

The model of the "simple language with clarifications" first-choice communication preference correctly predicted $77 \%$ of cases. Statistically significant variables with positive coefficients are: Q9, Q13, Q29, Q30, Q43, Q68; statistically significant variables with negative coefficients are: Q21, Q31, Q36, Q59, Q65, Q65. However, the LRT values suggest that the null - hypothesis should be rejected.

The model of the "simple, common language" first-choice communication preference correctly predicted $83 \%$ of cases. Statistically significant variables with positive coefficients are: Q17, Q21, Q31, Q44, Q51, Q53, Q59, Q60, Q61, Q65; and statistically significant variables with negative coefficients are: Q6, Q9, Q13, Q39, Q47, Q52.

The model of "expert language with clarifications" first-choice communication preference correctly predicted $89.1 \%$ of cases. Statistically significant variables with positive coefficients are: Q9, Q21, Q23, Q28, Q36, Q39, Q40, Q47, Q52, Q55; and statistically significant variables with negative coefficients are: Q3, Q4, Q18, Q24, Q29, Q42, Q44, Q46, Q61, Q68.

The model of "presenting own situation in detail regarding the motives, aims and desires" first-choice communication preference correctly predicted $86 \%$ of cases. Statistically significant variables with positive coefficients are: Q5, Q8, Q9, Q13, Q14, Q40, Q48, Q63, Q67; and statistically significant variables with negative coefficients are: Q3, Q15, Q25, Q35, Q37, Q51, Q61, Q66.

The model of "presenting the problem, motives and goal in a nutshell" first-choice communication preference correctly predicted $78.2 \%$ of cases. Statistically significant variables with positive coefficients are: Q3, Q15, Q17, Q34, Q35, Q37, Q62; and statistically significant variables with negative coefficients are: Q1, Q13, Q38, Q45, Q54, Q66.

The model of "presenting the problem in a short line, keeping the rest of information" first-choice communication preference correctly predicted $91.7 \%$ of cases. Statistically significant variables with positive coefficients are: Q7, Q20, Q31, Q37, Q38, Q45, Q49, Q54, Q59, Q64, Q66; and statistically significant variables with negative coefficients are: Q2, Q5, Q13, Q17, Q18, Q29, Q34, Q40, Q62, Q65.

\section{Discussion and Conclusion}

Given the digitalization of the modern world we encounter a situation of data overload while real, "face-to-face", communication diminishes. At this point, it is necessary to gain as much as possible information from the communication data, especially if the communication is digital. That might be one of the reasons for the necessity of quantification of the influencing factors on communication. Hence, it is only logical to pursue the quantification of the traits and biases which influence people's rationality and consequentially their choices.

The data used refers to 244 filled up questionnaires which have been collected online in period from March 2013 until May 2015 for Croatian population. Given that the questionnaire has been distributed online, the conclusions should be made only for the population which uses online services, which is in line with the research purpose. However, the conclusions should be derived only for a Croatian population, which represents a limitation of the study. Consumer behaviour is still heterogeneous due to cultural and income differences among countries (Anić et al., 2016).

Marketing experts should pay attention to the role of personal characteristics and demographics when formulating the communication messages (Mihić \& Kursan Milaković, 2017). Personality traits are represented as combined and weighted relative frequencies of the individual traits, and personality trait estimators are categorical variables coded as binary variables. The dependent variable represents choices of communication preferences regarding the communication approach, language use, and information sharing. Choices of consumer preferences act as a binomial variable where a certain choice occurs or doesn't occur. Binomial dependent variable enables the use of the logistic prediction models. 
This paper offers an econometric assessment of the personality estimators and traits correlation to consumer's first-choice communication preferences using linear logit model with binomial dependent variable. Beside the prediction of the communication style preferences, the research question of the paper was how deep analysis is necessary to increase prediction of communication preferences given the customers' personality traits/ biases and customers' personality estimators. The results point out that the more detail data provides more accurate predictions, to the point where is possible to determine correlation of specific personality estimators to a communication choice.

Even though there are many assessments using personality traits, the logistic regression showed that if we only have the knowledge of personality traits, communication preferences prediction will be low and inadequate.

Personality trait estimators can be used directly as communication preference predictors (as in second subsection of the results) and provide more relevant models with higher levels of prediction. That finding can be important nowadays, especially in digital marketing. It is hard to gather a full report on consumers' personality traits/type, but it is possible to gather or buy big data about some previous consumer choices and preferences. The list of statistically significant variables in model can be used as an assessment list for determination of communication approach, language use and information. Given that only personality traits/ biases are used, it represents a limitation of the study. From that limitation arises the possibility for the further research and to examine the influences of other biases, heuristics and cognitive illusions to communication choices.

Practical implications relate to the use of the findings in communication with consumers in face-to-face communication, but especially in online communication using the results as an input for the recommendation agents.

Theoretical implications of the findings request questioning of the use of the personality traits as an interim stage in decision-making predictions. In addition, these findings fill the gap in the field of communication preference based on personality traits and personality estimators.

\section{References}

Amiel, T., \& Sargent, S. L. (2004). Individual differences in Internet usage motives. Computers in Human Behavior, 20(6), 711-726. https://dx.doi.org/10.1016/j.chb.2004.09.002

Anić, I. D., Ciunova-Shuleska, A., Rajh, S. P., Rajh, E., \& Bevanda, A. (2016). Differences in consumer decision-making styles among selected south-east European countries. Economic research-Ekonomska istraživanja, 29(1), 665-681. https://doi.org/10.1080/133167 7X.2016.1193949.

Camerer, C. F. (1998). Prospect theory in the wild: Evidence from the field. In Choices, Values, and Frames. Contemporary Psychology. No. 47 (pp. 288-300). Washington, DC: American Psychological Association.

Davis, C., Patte, K., Tweed, S., \& Curtis, C. (2007). Personality traits associated with decision-making deficits. Personality and Individual Differences, 42(2), 279-290. https://dx.doi.org/10.1016/j.paid.2006.07.006.

Horvitz, E. J., \& Pennock, D. M. (2003). U.S. Patent No. 6,655,963. Washington, DC: U.S. Patent and Trademark Office.

Johnson, G. M., \& Johnson, J. A. (2006). Personality, Internet experience, and e-communication preference. In P. Isaias, M. B. Nunes, \& I. J. Martinez (Eds.), Proceedings of the IADIS International Conference WWW/ Internet 2006, Vol. 1 (pp. 55-62). Murcia, Spain: IADIS Press.

Kahneman, D. (2002). Maps of bounded rationality: A perspective on intuitive judgment and choice. Nobel prize lecture, 8, 351-401.

Kostelić, K. (2017). Modeling Interpersonal Marketing Communication in Sale Process Applying Behavioral Game Theory (Doctoral dissertation, Fakultet ekonomije i turizma" Dr. Mijo Mirković" u Puli, Sveučilište Jurja Dobrile u Puli).

Mihić, M., \& Kursan Milaković, I. (2017). Examining shopping enjoyment: personal factors, word of mouth and moderating effects of demographics. Economic research-Ekonomska istraživanja, 30(1), 1300-1317. https://doi.org/ 10.1080/1331677X.2017.1355255.

Mohlin, E. (2012). Evolution of theories of mind. Games and Economic Behavior, 75(1), 299-318. https://doi.org/10.1016/j. geb.2011.11.009.

Nassiri-Mofakham, F., Nematbakhsh, M. A., Ghasem-Aghaee, N., \& Baraani-Dastjerdi, A. (2009). A heuristic personality-based bilateral 
multi-issue bargaining model in electronic commerce. International Journal of HumanComputer Studies, 67(1), 1-35. https://doi. org/10.1016/j.jjhcs.2008.08.001.

Nassiri-Mofakham, F., Ghasem-Aghaee, N., Ali Nematbakhsh, M., \& BaraaniDastjerdi, A. (2008). A personality-based simulation of bargaining in e-commerce. Simulation \& gaming, 39(1), 83-100. https://doi.org/10.1177/1046878107308094.

Njegovanović, A., \& Ćosić, K. P. (2016). Causal Peer Effects in Financial Decision Making. Review of Innovation and Competitiveness: A Journal of Economic and Social Research, 2(1), 111-130.

Pratt, H. K. (1996). The electronic personality. Fielding Institute.

Roozmand, O., Ghasem-Aghaee, N., Hofstede, G. J., Nematbakhsh, M. A., Baraani, A., \& Verwaart, T. (2011). Agent-based modeling of consumer decision making process based on power distance and personality. KnowledgeBased Systems, 24(7), 1075-1095. https://doi. org/10.1016/j.knosys.2011.05.001.

Rubinstein, A. (1998). Modeling bounded rationality. MIT press.

Ryan, T., \& Xenos, S. (2011). Who uses Facebook? An investigation into the relationship between the Big Five, shyness, narcissism, loneliness, and Facebook usage. Computers in human behavior, 27(5), 1658-1664. https://dx.doi.org/10.1016/j.chb.2011.02.004.

Škare, M., \& Kostelić, K. (2015). Interpersonal Communication in the Internal Marketing: Bounded Rationality Game Theory Approach. Economic Computation \& Economic Cybernetics Studies \& Research, 49(4).
Villaume, W. A., \& Bodie, G. D. (2007). Discovering the listener within us: The impact of trait-like personality variables and communicator styles on preferences for listening style. The International Journal of Listening, 21(2), 102-123. https://doi. org/10.1080/10904010701302006.

Weaver III, J. B. (1991). Exploring the links between personality and media preferences. Personality and Individual Differences, 12(12), 1293-1299. https://doi.org/10.1016/01918869(91)90203-N.

Xiao, B., \& Benbasat, I. (2007). E-commerce product recommendation agents: use, characteristics, and impact. MIS quarterly, 31(1), 137-209.

Zafari, F., Moser, I., \& Rahmani, R. (2017). Proposing a highly accurate hybrid component-based factorised preference model in recommender systems. In Proceedings of the 26th International Joint Conference on Artificial Intelligence (IJCAI). https://dx.doi. org/10.24963/ijcai.2017/185.

Katarina Kostelić, Ph.D. Juraj Dobrila University of Pula Faculty of Economics and Tourism "Dr. Mijo Mirković" Croatia katarina.kostelic@unipu.hr

Danijela Križman Pavlović, Ph.D. Juraj Dobrila University of Pula Faculty of Economics and Tourism "Dr. Mijo Mirković" Croatia dkrizman@unipu.hr 


\section{Appendix: Personality traits estimators (Part 1)}

\begin{tabular}{|c|c|}
\hline Q1 & You like to be involved in active and dynamic activities and jobs. \\
\hline Q2 & You are almost never late for your meetings. \\
\hline Q3 & You enjoy having a wide circle of acquaintances. \\
\hline Q4 & You feel involved while watching TV soaps and series. \\
\hline Q5 & You are the first to react to sudden events, such as phone ringing or unexpected question. \\
\hline Q6 & You are more interested in general idea than the details regarding the implementation. \\
\hline Q7 & You tend to remain impartial even if it could endanger your good relations to people. \\
\hline Q8 & You find that following the rules strictly will probably prohibit good outcome. \\
\hline Q9 & It is hard to upset you. \\
\hline Q10 & It comes natural for you to take over responsibility. \\
\hline Q11 & You often think about mankind and its future. \\
\hline Q12 & You believe that the best decisions are those which are easy to change. \\
\hline Q13 & Constructive criticism is always useful. \\
\hline Q14 & You rather react immediately, than to estimate possible actions. \\
\hline Q15 & You prefer to trust reason over emotions. \\
\hline Q16 & You rely on improvisation, rather than on careful planning. \\
\hline Q17 & You spend your time actively socializing in a group of people. \\
\hline Q18 & Usually, you plan your activities ahead. \\
\hline Q19 & You often react based on emotion. \\
\hline Q20 & You are reserved and distanced person in communication. \\
\hline Q21 & You know how to use each minute in a day. \\
\hline Q22 & You willingly help people without asking anything in return. \\
\hline Q23 & You often consider complexities of life. \\
\hline Q24 & After longer socializing, you feel the need to leave and be alone for a while. \\
\hline Q25 & You often do chores in a hurry. \\
\hline Q26 & You easily notice general principles underlying certain event. \\
\hline Q27 & You express your feelings and emotions often and easily. \\
\hline Q28 & It is hard for you to speak up. \\
\hline Q29 & You find reading theoretical books boring. \\
\hline Q30 & You empathize with other people's situations. \\
\hline Q31 & You value the justice more over mercy. \\
\hline Q32 & On a new job, you will make friends very quickly. \\
\hline Q33 & You feel better when communicating with many people. \\
\hline Q34 & You prefer to rely on your own experience rather on theoretical possibilities. \\
\hline Q35 & You like to check how things progress during any process. \\
\hline Q36 & You easily empathize with other people worries. \\
\hline Q37 & You will prefer to read a book over going to the party. \\
\hline Q38 & You enjoy being under spotlight in events which include many people. \\
\hline Q39 & You prefer to try out something new, over doing the same thing over again. \\
\hline Q40 & You avoid being bounded by a commitment. \\
\hline
\end{tabular}




\begin{tabular}{|c|c|}
\hline Q41 & You are deeply touched by other people's stories. \\
\hline Q42 & You find deadlines to be rather a relative than a final due. \\
\hline Q43 & You prefer to isolate yourself from the outer sounds. \\
\hline Q44 & It is important for you to try out something with your own hands. \\
\hline Q45 & You think anything can be analysed. \\
\hline Q46 & You try hard to finish your obligations in time. \\
\hline Q47 & You find joy in establishing the order. \\
\hline Q48 & You feel relaxed in a crowd. \\
\hline Q49 & You are in control over your desires and temptations. \\
\hline Q50 & You easily understand theoretical principles. \\
\hline Q51 & The process of finding the solution is more important than the solution itself. \\
\hline Q52 & You rather place yourself in a corner of a room than in the centre. \\
\hline Q53 & When solving problems, you will rather use an already tested approach, than to try out a new one. \\
\hline Q54 & You firmly stick to your principles. \\
\hline Q55 & You are often eager for new adventures and events. \\
\hline Q56 & You rather spend time with a few chosen people than in a bigger company. \\
\hline Q57 & $\begin{array}{l}\text { When thinking about a situation, you pay more attention to current situation over possible } \\
\text { future events. }\end{array}$ \\
\hline Q58 & You think that scientific approach is the best approach. \\
\hline Q59 & It is hard for you to talk about feelings. \\
\hline Q60 & You often spend time thinking how something could be improved. \\
\hline Q61 & Your decisions depend more on a current mood than careful planning. \\
\hline Q62 & You like to spend your spare time alone or in a peaceful family atmosphere. \\
\hline Q63 & You find more comfort in following usual, generally accepted patterns. \\
\hline Q64 & You get under influence of the fierce emotions. \\
\hline Q65 & You always search for the new opportunities. \\
\hline Q66 & Your work place or working table are usually clean and neat. \\
\hline Q67 & In general, you are more concerned about current activities than the future events. \\
\hline Q68 & You enjoy lonely walks. \\
\hline Q69 & You easily communicate in the social interactions. \\
\hline Q70 & You are consistent in your habits. \\
\hline Q71 & You love to include in conversations about the topics which interest you. \\
\hline Q72 & You easily anticipate the ways of how the situation can develop. \\
\hline
\end{tabular}




\section{Abstract}

\section{ECONOMETRIC ASSESSMENT OF CUSTOMERS'PERSONALITY BIASES AND COMMUNICATION PREFERENCES CORRELATION}

\section{Katarina Kostelić, Danijela Križman Pavlović}

The tendency of bias identification and quantification with the goal of better estimation and prediction, grows. The purpose of this paper is to question how deep analysis is necessary to increase prediction of communication preferences given the customer's personality traits/biases. Examined communication preferences regard to the communication approach, language use and information sharing.

This paper offers a psychometric assessment of the personality estimates and traits, as well as econometric examination of correlation to consumer first-choice communication preferences using linear logit model with binomial dependent variable.

The results point out that the more detail analysis provides more accurate predictions, to the point where estimators as regressors for communication choices provide more accurate prediction than the use of the personality traits as independent variables.

Paper delivers empirical assessment of consumers' communication preferences using primary data set. Practical implications relate to the use of the findings in communication with consumers in online and/ or digital marketing communication. One of the possible practical use of the results can be as an input for the recommendation agents. Theoretical implications of the findings request questioning the use of the personality traits as an interim stage in decision-making predictions. In addition, these findings fill the gap in the field of communication preference based on personality traits and personality estimators.

The data set has been previously used for the doctoral thesis research. For the purpose of this research, data was re-coded and analyzed using different approach, namely binomial logistic regression.

Key Words: Personality traits/biases, logistic regression, consumer decision-making, communication preferences.

JEL Classification: C35, D91, M31.

DOI: 10.15240/tul/001/2018-3-009 